\title{
GALLOIS, Dominique Tilkin; MACEDO, Valéria. 2018. Nas redes guarani: saberes, traduções e transformações. São Paulo: Hedra. 374 pp.
}

\author{
Hugo SALUSTIANO \\ Universidade de São Paulo | São Paulo, SP, Brasil \\ hugosalustiano@gmail.com \\ MARIA CAROLINA BOTINHON DE CAMPOS iD \\ Universidade de São Paulo | São Paulo, SP, Brasil \\ mariacbotinhon@gmail.com
}

DOI 10.11606/issn.2316-9133.v30i1pe185798

É famosa na etnologia guarani a afirmação com que Nimuendaju (1987: 3) inicia sua monografia: tão conhecidos seriam os Guarani que seria supérfluo lhes dedicar mais páginas. A lembrança desta afirmação tornou-se lugar comum pela ironia proposital que carrega: Nimuendaju não só construiria novas compreensões sobre as coletividades guarani e as relações que estabelecem entre si, com os não indígenas e com o Estado, como faria emergir questões mobilizadoras até hoje (Viveiros de Castro, 1987: xxvii).

Mais de um século depois, é publicada a coletânea "Nas redes guarani: saberes, traduções e transformações” (2018), organizada por Dominique Gallois e Valéria Macedo, fruto do encontro entre antropólogos não indígenas e cineastas, professores, pesquisadores acadêmicos e lideranças do povo Guarani no simpósio “CEstA nas Redes Guarani”, realizado pelo Centro de Estudos Ameríndios da Universidade de São Paulo (CEstA-USP) em 2013. A coletânea busca traduzir para um público amplo produções contemporâneas derivadas da interlocução entre pesquisadores acadêmicos e coletivos guarani e se centra apenas em uma parte das extensas redes guarani, hoje compostas por mais de 280 mil pessoas vivendo num amplo território atualmente sobreposto por Paraguai, Bolívia, Argentina e Brasil (Equipe Mapa Guarani Continental, 2016).

O conjunto de traduções cuidadosas dos múltiplos aspectos da vida guarani não é apresentado, contudo, de modo por assim dizer "didático", pois o livro traz 25 textos de diferentes autores indígenas e não indígenas, com diversas formações, embora a maioria seja de antropólogos. A esses textos somam-se duas cartas-manifesto com remetentes e destinatários 
coletivos: a carta da Comissão Guarani Yvyrupa, que acompanha o texto de Marcos dos Santos Tupã, e a "Carta pública em defesa dos direitos do povo Guarani”. Mais do que explicar o que seriam as redes guarani, esse conjunto de artigos parece mostrar em sua heterogeneidade as formas que estas redes podem tomar, justapondo-se e conectando-se de modos variáveis. Sugerindo a proficuidade de novas abordagens para pensar as socialidades guarani, os textos também renovam temas clássicos.

Um desses temas é a questão territorial. Nimuendaju (1987 [1914]: 8-16) apresentava descrições de um momento-chave das respostas violentas de autoridades brasileiras e paraguaias frente à mobilidade de grupos guarani. Era o tempo em que se desenhava aquilo que viria a ser uma política estatal de delimitação de terras em áreas reservadas pelo Estado ${ }^{1}$ dentro das quais deveriam viver populações indígenas. A primeira seção da coletânea, "Movimentos pela terra, andanças entre mundos”, fornece um contraponto a essas políticas ao comentar as lutas contemporâneas de coletivos mbya, kaiowa e nhandeva ${ }^{2}$ para exercerem seus modos próprios de ser e estar no mundo ( $n$ handereko ou ore ava reko), e as estratégias mobilizadas para garantir seus direitos territoriais, nas quais estão implicados modos próprios de conceber sua territorialidade e a política.

Com Marcos Tupã e Daniel Pierri vemos a centralidade da noção de yvyrupa para compreender a estratégia política mbya. De acordo com Tupã (:28), yvyrupa remete, entre outras coisas, à ideia de que para os Mbya a terra, gerada por Nhanderu, o demiurgo, "é uma só, não se limita (...) nessas divisas políticas”, e foi assim feita para “todos os povos viverem”. Esta noção é mobilizada para reivindicar de modo crítico as demarcações de Terras Indígenas, pois se deve demarcar não para confinar, mas para garantir a circulação dos Guarani pelo amplo território

\footnotetext{
${ }^{1}$ Num sentido diverso do que seria a demarcação de terras pós-Constituição de 1988. No início do século XX, a criação do Serviço de Proteção ao Índio marcava um momento da política indigenista brasileira de caráter tutelar e que oficializou um projeto integracionista, cedendo a interesses econômicos públicos e privados. Esta política foi gestada em meio a uma série de empreendimentos que promoviam esbulhos territoriais, confinamentos e violências com efeitos adversos para os Guarani e outros povos indígenas, processos caracterizados como "grave violação de direitos humanos" pelo relatório da Comissão Nacional da Verdade (Brasil, 2014). Para um panorama histórico das disputas em torno dos direitos dos povos indígenas, ver Carneiro da Cunha (2018) e a coletânea de Carneiro da Cunha e Barbosa (2018).

${ }^{2}$ Mbya, Nhandeva e Kaiowa são algumas das denominações mobilizadas pela etnologia para tentar caracterizar diferentes coletivos Guarani no Brasil, que se distinguiriam "por diferenças sobretudo linguísticas, mas também por peculiaridades na cultura material e não-material” (Schaden, 1954: 2). No entanto, como veremos ao longo desta resenha, essas "parcialidades" não podem ser tomadas como homogêneas ou estáveis. Há uma proliferação de denominações e variações culturais, além de afastamentos e proximidades distintas em cada contexto local, discussão vista em artigos da última seção da coletânea. Cabe observar aqui que, em Mato Grosso do Sul, a diferenciação entre coletivos Kaiowa e Nhandeva é operada, respectivamente, sob as denominações Kaiowa e Guarani; e que alguns coletivos considerados Nhandeva são denominados Tupi Guarani. Nesta resenha, respeitamos os etnônimos empregados pelos autores.
} 
percorrido pelos antepassados e a continuidade das redes guarani. ${ }^{3}$ Como nota Pierri, não é à toa que a noção de yvyrupa servirá para compor parte do nome da organização política Comissão Guarani Yvyrupa, fundada em 2006 e sobre a qual fala Tupã, um de seus cofundadores. A estratégia da organização é, justamente, superar a fragmentação dos movimentos guarani no Sul e Sudeste e articular um enfrentamento contra o não reconhecimento das terras guarani e os empreendimentos que as impactam.

Alguns desses aspectos da territorialidade guarani - movimentação sobre território amplo - já eram vislumbrados em Nimuendaju (1987 [1914]), que se notabiliza por articular as migrações a um motivo cosmológico: a busca da "Terra sem Mal” ( yvy marã e’ÿ), dimensão de abundância, renovação e imortalidade das cosmologias guarani, atingível a partir de certas práticas de imitação das divindades que levam à "maturação corporal" (aguyje) (Pierri, 2013). Se a contribuição de Nimuendaju é importante por incluir algo do ponto de vista dos Guarani sobre seus próprios movimentos no debate sobre as "causas" das migrações, o revés foi, ao longo do tempo, sua caracterização como um povo "religioso". É uma crítica a esses excessos interpretativos sobre esse importante tema o que busca Spensy Pimentel em seu texto.

O autor analisa a "busca da Terra sem males" a partir do violento contexto que enfrentam os Kaiowa e Guarani no Mato Grosso do Sul. Entre eles, diz Pimentel, a “Terra sem Males” não se atinge migrando rumo a leste em direção ao mar, como no caso mbya, mas sim "rompendo a cerca dos latifúndios" (:46). Os discursos xamânicos kaiowa e guarani revelam que o lugar de festa e fartura a ser alcançado são as próprias terras a serem demarcadas, os tekoha, lugares onde se poderá retomar o "bom costume" (teko porã) dos antepassados. A restituição dos tekoha pela qual lutam, portanto, é alcançável através da política, segundo o autor; deslocar este projeto para a transcendência - descrevendo-o como "utopia religiosa" - é recusar a possibilidade de alternativas de vida frente à exploração capitalista e à destruição ambiental.

Depreende-se, portanto, que não se trata de privilegiar um ou outro plano da realidade, e sim a imbricação de vários planos que conceitos modernos demarcam como distintos. Para os Guarani a política é indissociável da conexão com entidades mais-que-humanas, como divindades, antepassados e espíritos-donos. Tonico Benites exemplifica esta lógica no encerramento da seção. O autor relata a história da ocupação kaiowa e guarani na região entre o que hoje é Brasil e Paraguai, e a expulsão de suas terras, com o confinamento em reservas empreendido no século XX. Em seguida, detalha os Jeroky Guasu ("grande ritual religioso") e as Aty Guasu ("grande assembleia"), encontros realizados a partir dos anos 1980, com a participação de lideranças espirituais ( ñanderu) e políticas. O que se vê é uma espécie de retroalimentação entre esses encontros: são voltados para o fortalecimento do ava reko, modo de viver kaiowa e

\footnotetext{
${ }^{3}$ Nem sempre foi assim: em dado ponto da história, práticas territoriais guarani passavam ao largo da articulação política em torno da luta por demarcação, o contrário do que se vê hoje - o que denota a constante atualização das respostas guarani frente a diferentes conjunturas (cf. Ladeira, 2007: 69; Brand, 1997: 105-107).
} 
guarani, e para as retomadas dos tekoha que compunham o tekoha guasu, o território tradicional. Com Benites, percebe-se que a possibilidade de retomada territorial depende do "fortalecimento espiritual" coletivo e vice-versa.

Outro tema clássico que não cessa de se desdobrar em novas análises é a centralidade da relação com os mais velhos e com parentes, que fazem circular os conhecimentos provenientes de suas próprias caminhadas e da comunicação com as divindades, servindo de modelo aos mais jovens. Na segunda seção, "Caminhos e conhecimentos", são aprofundados alguns modos guarani de conhecer, de se relacionar e agir importantes para o fortalecimento do teko (modo de ser) e para fazer frente a relações potencialmente deletérias, principalmente no contato com o mundo jurua (não indígena).

Um desses modos de conhecer é o sonho, mostra Karai Mirim (Algemiro da Silva). Os sonhos são associados às caminhadas e fundações de aldeias, permitindo um vislumbre do lugar ideal onde fazer morada (tekoa), além de serem meio de saber sobre doenças, caça e quando uma criança nascerá. Há, contudo, uma tensão que percorre o texto de Karai Mirim: a possibilidade de se parar de "sonhar em Guarani" (:79) que é vivida por ele nos percursos junto aos jurua durante sua formação como pesquisador universitário. A questão da (ir)reversibilidade das transformações em outro ressoa temas clássicos da etnologia - como o da "aculturação" em Schaden (1954) ou da "desnaturação" do social em Clastres (1980). Aqui se veem respostas guarani para estas questões: a reativação do modo de vida guarani é possível a partir da boa conjunção com parentes e amigos, como explicitado por Jera Poty Mirĩ (Giselda Pires de Lima) no texto seguinte.

A autora fornece subsídios para pensar essa reativação a partir de reflexões sobre o "despertar" do xondaro, conceito complexo que designa, entre outras coisas, tanto uma dança voltada ao fortalecimento espiritual, força e leveza corporal quanto os próprios praticantes dessa dança. Comum em sua infância, a prática foi "adormecendo" ao longo dos anos em sua aldeia. A dinâmica do "adormecer" e "despertar" reflete certo modo guarani de pensar práticas e conhecimentos, oferecendo uma contraleitura das interpretações aculturativas. Pensando com Jera Poty Mirĩ, os conhecimentos guarani não se criam do nada, tampouco desaparecem por completo; sua ativação ou inativação depende de composições entre pessoas, coletivos e ambiente. No caso relatado pela autora, os jovens se fortaleceram no xondaro a partir da troca com amigos vindos de outras aldeias e, então, ajudaram a fortalecer o xondaro em outros lugares. Essas trocas em rede se desdobram no aumento do cuidado mútuo entre parentes e amigos nas comunidades e no fortalecimento das retomadas de terras e dos movimentos pela demarcação.

No sonho e no xondaro são vislumbrados aspectos das práticas guarani de conhecimento fortemente distintos daqueles hegemônicos na educação escolar. Tal distintividade pode ser vista na afirmação de Jera Poty de que a escola faz perder "a delicadeza em se respeitar o seu momento" (:90) com as inúmeras regras que é capaz de impor. Na sequência, Alice Haibara 
mostra que o modo da escola de organizar a experiência do conhecimento - horários rígidos, controle de frequência, exigência de um saber homogêneo, reunião de muitas kyringue (crianças) num ambiente só - é bem diferente de como as kyringue aprendem no contexto extraescolar. Nos mundos mbya, prossegue Haibara, o conhecimento é mais bem compreendido como o percorrer de um caminho que se faz junto a outras pessoas, em que as crianças possuem autonomia para escolher onde, em que momento e com quem aprenderão. Se por um lado há um ideal de que o aprendizado de uma atividade se dá junto a alguém ou na imitação da maneira como alguém mais velho ou mais habilidoso leva essa atividade a cabo, é à maneira de cada um que a atividade é experimentada e aprendida de fato. Neste sentido, em brincadeiras entre si ou na convivência com os mais velhos na opy (casa de reza), a imitação de atividades pelas crianças guarani implica não só tomá-las como modelo fixo, mas transformá-las, sendo a criação da diferença um processo da própria aprendizagem.

Além disso, a distintividade entre essas práticas de conhecimento passa pelo fato de que para construí-las - para "caminhar" - é central a atenção à corporalidade, presente desde o momento em que se tem notícia da concepção de uma pessoa, como mostra Adriana Testa. Entre os Mbya, aponta a autora, o crescimento da pessoa e sua permanência na terra depende, antes de tudo, do contínuo fortalecimento do vínculo entre seu nhe' ẽ (alma-palavra) e ete (corpo), vínculo que se fortalece por meio de práticas de produção de semelhanças corporais e comportamentais entre a pessoa e seus parentes humanos e de produção de diferenças em relação a outros tipos de gentes, que tentam levá-la do convívio dos vivos.

Antecipando o tema das relações de alteridade, o artigo de Testa é ponte para a terceira seção, "Conexões, alteridades, alterações". Esta seção aborda a centralidade da relação com as divindades, sendo a imitação de seus modos de vida nas moradas celestes um modo de se manter alegre entre parentes e enfrentar desafios que se colocam na morada terrestre. Nesta última, a pessoa é mais vulnerável a acontecimentos trágicos e ao ataque de seres que podem gerar transformações interespecíficas indesejáveis (-jepota), causando a morte.

Ana Ramo y Affonso enfatiza como a lembrança das palavras dos mais velhos e da socialidade celeste do nhe' 'é, aliada ao esquecimento dos mortos e de parentes que se afastaram, são necessárias para fortalecer as relações desejadas entre humanos e bloquear relações indesejadas com não-humanos. Entre os Mbya, estados como a tristeza, a saudade e a raiva são concebidos como caminhos por onde circulam perigosos espectros dos mortos (ãgue kuery) que tentam levar os vivos. Por sua vez, Elizabeth Pissolato demonstra que a alegria (-vy'a), estado correlativo ao "acostumar-se" necessário para que se queira ficar num determinado lugar, também é um afeto que motiva mudanças de quem busca alegrar-se com parentes de outros lugares. A alegria aparece, portanto, como uma das molas propulsoras da movimentação mbya pelo território e da produção do parentesco. 
Os dois textos seguintes investigam as relações de alteridade com os não indígenas. Fabio Nogueira analisa como parentes se mobilizam para fundar aldeias (tekoa) em lugares apontados pelas divindades em sonhos e visões, lugares propícios ao fortalecimento para se atingir o estado de aguyje, por reunirem as condições de comunicação dos Guarani com os diversos seres celestiais e terrestres. O tekoa, então, seria o oposto da cidade: segundo o autor, é lugar propício às comunicações, enquanto a vida jurua em prédios em que as pessoas não se conhecem produz pessoas ensimesmadas. Já Valéria Macedo se debruça em seu texto sobre uma certa lógica mbya de relação de alteridade orientada pela tentativa de não se deixar estabilizar nem na posição de presa, nem na de predador, "promovendo capturas parciais e circulando nas redes sem ser enredado" (:192). Este movimento é importante pois o mundo jurua é perigoso, mas oferece potencialidades - "projetos", mercadorias, aliados - das quais é interessante se apropriar cuidadosamente, aponta a autora.

Encerrando a seção, Renato Sztutman fornece um bom ponto de parada: demonstra a atualidade da proposta clastreana de diálogo entre regimes de pensamento, enfatizando a potência político-epistemológica (Viveiros de Castro, 2002) das falas xamânicas. Tais como as falas de Davi Kopenawa, as falas de xamãs com quem Clastres conviveu podem ser lidas, segundo Sztutman, como discursos cosmopolíticos que permitem vislumbrar outros modos de vida e a crítica a uma modernidade insistente em tentar dizimá-los.

Em um dos comentários que preenchem os interstícios dos artigos da coletânea e retomam os debates do simpósio, Dominique Gallois lembra que os Guarani operam não por separações, e sim por simultaneidades, entre passado e presente, tradição e modernidade (:210), apontando para as reflexões da quarta seção. Sob o título "Tecnologias, circulação e transformação", ela reúne textos sobre aspectos processuais que envolvem os usos de tecnologias de comunicação como forma de manejar relações, de mobilizar e transformar redes. Papa Mir̃ Poty (Carlos Fernandes) e Kuaray Poty (Ariel Ortega) mostram, a partir de suas próprias experiências e obras audiovisuais, como fazer filmes envolve relações de confiança com as comunidades filmadas. Seus textos convergem ao apontar que essa confiança é construída com o reconhecimento de que a sensibilidade e a temporalidade guarani não deixam de operar quando a apropriação cuidadosa faz dessa tecnologia um instrumento através do qual o nhandereko pode ser expresso. Referindo-se a formas de se expressar em suas produções audiovisuais, Carlos Papa afirma: "o mito apresenta muito a vida da gente hoje" (:241). E Ortega observa: quem filma é "uma pessoa que está ali querendo conversar com os mais velhos" (:234); o processo de registro e de exibição do filme são "uma outra forma de ficar escutando as histórias” (:237).

Na mesma direção, Lucas Keese e Wera Alexandre apresentam uma autocrítica aos contextos de formação em vídeo, que muitas vezes priorizam apenas as etapas de captação, sendo as etapas de edição do material deixadas em segundo plano. Os autores comparam a autonomia 
nas experimentações de linguagem no processo de montagem, que culminam na construção do discurso audiovisual, aos processos de maturidade pelos quais passam os Mbya ao longo da vida para saber se colocar e falar aos demais. E fazem coro a Ortega: mostrar na tela os sentidos das caminhadas e dos movimentos que conformam sua territorialidade e o nhandereko também é um meio de educar auditórios não indígenas.

Tatiane Klein apresenta um relato etnográfico sobre equívocos operantes em um encontro entre realizadores da Associação Cultural de Realizadores Indígenas do Mato Grosso do Sul (Ascuri) e uma equipe de televisão do povo Māori interessada em produzir notícias sobre os Kaiowa e Guarani para povos indígenas no Pacífico. Ao perseguir repercussões e processos de produção de conteúdo, a autora reflete sobre especificidades e diferenças entre práticas midiáticas. Comparando-os às ações das Aty Guasu, a autora sublinha que os modos kaiowa e guarani de produzir informação por meio da Ascuri envolvem tentativas de controle de equívocos para produzir relações eficazes com potenciais aliados e em suas próprias comunidades, dado que, localmente, fomentam espaços de reflexão sobre suas experiências de apropriação de tecnologias de comunicação não indígenas - ponto de desencontros de expectativas entre gerações, que expõem coerências e dilemas próprios.

Maria Inês Ladeira encerra a seção com uma atenciosa descrição dos embasamentos cosmológicos que orientam formas de relação em yvy vai, mundo terrestre marcado pela transitoriedade (:265). Narrativas míticas sobre a origem da humanidade na terra, mobilizadas pela autora, prescrevem a importância dos núcleos familiares guarani se comunicarem entre si. Ao povoarem yvyrupa se separam, mas se mantêm conectados por redes de reciprocidade que impulsionam seus movimentos e fazem circular pessoas, memórias, saberes, cultivos, notícias de parentes e do mundo em geral. Observando que, ao utilizarem as tecnologias dos não indígenas, os Guarani “não deixam de ouvir a voz de Nhanderu ou receber suas palavras” (:269) um interlocutor de Ladeira a leva à reflexão de que os diferentes modos de comunicação, ao invés de excludentes, são "domínios permeáveis" (:274).

A última seção do livro, "Nas aldeias e entre aldeias", traz discussões sobre o clássico tema das parcialidades guarani e sobre formas de organização social. Levi Marques Pereira abre a seção contribuindo com o tema da mobilidade a partir de considerações sobre três modalidades de assentamento kaiowa e guarani em Mato Grosso do Sul: as reservas, delimitadas no início do século XX e ocupadas até hoje por parte da população guarani naquele estado, e áreas recentemente configuradas, compostas por acampamentos de retomadas e periferias de cidades. Segundo Pereira, as novas modalidades de assentamento demonstram a persistência da busca kaiowa e guarani pela reprodução de seu espaço social fora dos limites e conflitos impostos pelas condições de vida nas reservas. A atualização de estratégias acionadas por lideranças para "orientar sua criatividade para efetivarem a existência de seus coletivos, ou como denominam, levantar a comunidade, opu'ã che réyi kuera" (:287) são respostas a essa conjuntura. 
Diogo Oliveira busca compreender como a constituição de redes e a mobilidade guarani conformam a parcialidade tradicionalmente classificada como Nhandeva. Seu texto mostra como a diversidade de composições das parcialidades guarani se transformam em meio a processos históricos, dinâmicas territoriais e alianças políticas. A partir de um apanhado das investigações que se debruçaram sobre tentativas de definições das parcialidades guarani, o autor desenvolve considerações sobre seus limites e possibilidades de reflexão.

Já Lígia Almeida, Amanda Danaga e Camila Mainardi exploram o conceito de "mistura" operado por famílias tupi guarani no estado de São Paulo. Por meio desse conceito, os Tupi Guarani fazem uma crítica às tentativas de essencialização de parcialidades guarani e, no polo oposto, à noção de aculturação - fontes de diversos preconceitos que atingem os povos indígenas. Ao se afirmarem Tupi Guarani, essas famílias expressam sua singularidade, cujo fortalecimento está ligado ao território: o que importa é garantir os sentidos da vida compartilhada em suas aldeias ao "falar a língua ou respeitá-la, alimentar-se com o que cultivam, ficar junto aos parentes, cuidando e sendo cuidado” (:326). Esse processo não deixa de estar atravessado por relações com os não indígenas, com outros povos indígenas e outros coletivos guarani. Recusando perspectivas estereotipantes, os Tupi Guarani convocam a encarar a "mistura" como movimentos entre relações de aliança e distanciamento, em que ocorre a atualização e a proliferação da diferença, e não a sua supressão.

Ao acompanhar as rotas traçadas recentemente pelos Mbya que desceram o Rio Araguaia, no século passado, rumo à região Norte do Brasil, Rafael Mendes Júnior relaciona as redes de parentesco à mobilidade guarani, fazendo ecoar as descrições de Pissolato sobre alegria, parentesco e multilocalidade. Encerrando a seção, Donatella Schmidt retrata como um processo de reconhecimento interno de lideranças em aldeias mbya em Missiones (Argentina), em meio a inovações na legislação indigenista da região, é atravessado por constantes reavaliações sobre estratégias de distanciamento e aproximação com os não indígenas.

Por meio do kuaxia - o papel - a coletânea veicula também memórias das intensas mobilizações políticas feitas pelos Guarani em 2013 e em anos anteriores. Os textos colocam o leitor em contato com processos históricos e dinâmicas sociais que acarretaram - e acarretam inúmeras perdas territoriais para os Guarani; e é de se notar o fato de várias reflexões serem frutos de grupos de trabalho de demarcação de terras e de articulações políticas em defesa de seus territórios. Em meio a desafios e atropelos impostos por novas lógicas espaciais (Gallois, 2004), o livro mostra como os Guarani buscam vigorar suas territorialidades, sendo a intensa mobilidade uma importante forma de sua expressão.

Avisam as organizadoras no prefácio que "Guarani é uma designação que não dá conta da multiplicidade de coletivos e seus muitos caminhos”, nomeando de Guarani as redes em que esses coletivos emergem "e não aos grupos, cujos nomes são variados e variáveis" (:9). Esta é uma das questões mais espinhosas da etnologia guarani e, também, debate entre os Guarani, 
figurando como questão insolúvel na abertura de várias monografias dedicadas a esses povos. Além de figurar na abertura, é possível pensar que a questão do etnônimo figura como abertura, como lugar a partir do qual outras coisas são engendradas. Dessa forma, etnônimos e expressões a eles correlatas - que são por vezes mobilizados pelos próprios Guarani - são aqui empregados como mero ponto de apoio para abrir uma discussão que ao fim mostrará uma multiplicidade que desestabiliza esses mesmos nomes e expressões.

O ponto para o qual os Guarani parecem chamar a atenção - em sua intensa circulação por aldeias e em suas lutas para retomar terras; em suas trajetórias, modos de contar histórias e de levantar morada; na multiplicidade de meios de comunicação com divindades; em casamentos com pessoas de diferentes coletivos guarani e não guarani; na apropriação das tecnologias e políticas públicas não indígenas - é que, em seu mundo, são redes de relações que importam, redes que transformam e nas quais se entretecem pessoas, coletivos (humanos e não-humanos) e o próprio mundo. $\mathrm{O}$ intenso fluxo que percorre estas redes e os modos particulares de estabelecer os necessários pontos de parada tornam obsoletas noções estanques sobre "o que é” um coletivo ou uma pessoa guarani.

Esta é uma das lições gerais que se pode apreender desta coletânea. Por um lado, e apesar de seu título, ela não se detém em teorizar explicitamente interpelações entre uma noção de rede e as socialidades guarani. Mas, por outro lado, e em consonância com seu título e com sua heterogeneidade, ela fornece subsídios para caminhar neste sentido. Menos por defeito do que pela impossibilidade da tarefa, estes artigos são apenas um breve vislumbre dos muitos movimentos que os Guarani efetuam na contemporaneidade. Movimentos cuja potência na academia cada vez mais se faz ouvir, na medida em que aumentam as contribuições dos próprios acadêmicos guarani (e de outros povos indígenas) a estes debates. O que só aprofunda a ironia de Nimuendaju: hoje, mais do que nunca, percebe-se que a etnologia jamais será capaz de dizer coisas suficientes sobre os Guarani.

\section{Referências Bibliográficas}

BRAND, Antonio J. 1997. O impacto da perda da terra sobre a tradição kaiowá/guarani: os difíceis caminhos da palavra. Tese de Doutorado. Porto Alegre: Pontifícia Universidade Católica do Rio Grande do Sul.

BRASIL. 2014. Comissão Nacional da Verdade. "Texto 5 - Violações de direitos humanos dos povos indígenas”. In: COMISSÃONACIONAL DA VERSDADE. Relatório: textos temáticos. v. 2. Brasília: Comissão Nacional da Verdade. pp. 203-262.

CARNEIRO DA CUNHA, Manuela. 2018. Índios na Constituição. Novos estudos CEBRAP, v. 37, n. 3: 429-443. 
CARNEIRO DA CUNHA, Manuela; BARBOSA, Samuel (Orgs.). 2018. Direitos dos povos indígenas em disputa. São Paulo: UNESP.

CLASTRES, Pierre. 2004. Arqueologia da violência: pesquisas de antropologia política. São Paulo: Cosac Naify.

GALLOIS, Dominique Tilkin.2004. “Terras ocupadas? Territórios? Territorialidades?”. In: RICARDO, Fany (Org.). Terras indígenas \& unidades de conservação da natureza. São Paulo: Instituto Socioambiental: pp.37-41.

LADEIRA, Maria Inês. 2007 [1992]. O caminhar sob a luz: o território mbya à beira do oceano. São Paulo: Ed. Unesp/CTI/Fapesp.

EQUIPE MAPA GUARANI CONTINENTAL. 2016. Caderno Mapa Guarani Continental: povos Guarani na Argentina, Bolívia, Brasil e Paraguai. Campo Grande: Equipe Mapa Guarani Continental.

NIMUENDAJU, Curt Unkel. 1987 [1914]. As lendas da criação e destruição do mundo como fundamentos da religião dos Apapocúva-Guarani. São Paulo: Hucitec/Edusp.

PIERRI, Daniel C. 2013. O perecível e o imperecível: lógica do sensível e corporalidade no pensamento Guarani-Mbya. Dissertação de Mestrado. São Paulo: Universidade de São Paulo.

SCHADEN, Egon. 1974 [1954]. Aspectos fundamentais da cultura guarani. São Paulo: Universidade de São Paulo.

VIVEIROS DE CASTRO, Eduardo. 1987. “Nimuendajú e os Guarani”. In: NIMUENDAJU, Curt Unkel. As lendas da criação e destruição do mundo como fundamentos da religião dos ApapocúvaGuarani. São Paulo: Hucitec/Edusp. pp.xvii-xxxviii.

VIVEIROS DE CASTRO, Eduardo. 2002. O conceito de sociedade em antropologia. In: VIVEIROS DE CASTRO, Eduardo. A inconstância da alma selvagem e outros ensaios de antropologia. São Paulo: Cosac Naify.

\section{resenhistas}

\section{Hugo Salustiano}

Mestrando em Antropologia Social pela Universidade de São Paulo. Desenvolve uma pesquisa bibliográfica sobre os sonhos entre os povos Guarani.

\section{Maria Carolina Botinhon de Campos}

Graduada em Ciências Sociais pela Universidade de São Paulo. Faz parte da equipe da Ação Saberes Indígenas na Escola (ASIE/MEC) - Núcleo USP, que atua nas terras indígenas Jaraguá, Tenondé Porã e Ribeirão Silveira (SP). 
Contribuição de autoria: A concepção, redação e análise presentes no manuscrito são de responsabilidade de Hugo Salustiano e Maria Carolina Botinhon de Campos.

Financiamento: Hugo Salustiano contou com financiamento da Fundação de Apoio à pesquisa do Estado de São Paulo (Processo FAPESP: 2019/04636-3)

Recebido emo 12/04/2021

Aprovado em em 22/06/2021 